\title{
NOTAS SOBRE OS CROMOSSOMIOS DOS PROSCOPIIDIOS
}

\author{
Yone G. Penteado de Castro \\ Da Cadeira de Zoologia da Es- \\ cola Superior de Agricultura \\ "Luiz de Queiroz", da Univer- \\ sidade de S. Paulo
}

Em 1943 o PROF. S. de TOLEDO PIZA descreveu e figurou pela primeira vez, os cromossomios de Proscopidala, estudando as espécies Cephalocoema zilkari Piza e Tetanorhynchus mendesi Piza $=$ (Cephalocoema sica Serv.). Essas duas espécies tem o mesmo número de cromossómios, 17, sendo 8 pares de autossomios e um heterocromossomio, que se comportam de maneira semelhante em ambas.

Em um trabalho mais recente, 1945, o PROF. PIZA, estudando as mesmas espécies, observa que o heterocromossomio, na anáfase, encontra-se numa das placas conjuntamente com os autossomios (sincronismo) ou entre as placas (sucessão), ou ainda, algumas vezes, na metáfase, um pouco fora da placa equatorial.

Tive a oportunidade de estudar uma outra espécie da mesma familia, Cephalocoema borellii (Giglio-Tos). Nessa espécic os cromossomios diferem dos das outras duas apenas quanto ao número, havendo um par de autossomios a mais.

Cephalocoema borellil apresenta 19 autossomios perfeita- 
mente distintos na metáfase dos espermatogonios, sendo 9 pares de autossomios e um heterocromossómio. (Fig. 1).

Assim que o espermatócito primário inicia a 1.a divisão, o heterocromossomio destaca-se do emaranhado de leptonemas, como uma mancha colorida, lateralmente no núcleo. Nas vistas polares da metáfase distinguem-se 4 tétrades maiores, 5 menores e o heterocromossomio mais fracamente colorido (Fig. 2). Em vistas laterais este ultimo fol observado como um bastonete mais claro e de contorno menos definido, na placa equatorial, entre os autossomios (Fig. 3). Este bastonete divide-se multo cedo, apresentando-se na anáfase em forma de $\mathrm{V}$, com os dois r\&mos geralmente muito aproximados. (Fig. 4).

Nas anáfases, mesmo nas mais adiantadas, podem-se distinguir os dois membros de cada par de autossómios. Os elementos maiores levam mais tempo para se separar, tendo sido encontradas anáfases incipientes ainda com um ou dois pares de autossomios ligados na placa equatorial. O heterocromossomio caminha junto com uma das placas ou então atraza-se, apresentando-se em sucessáo, como um V, entre as placas que se dirigem para os polos. (Fig. 4).

Em vistas polares da metáfase secundária contam-se perfeitamente os cromossomios, tendo sido encontrados, como era de se esperar, espermatócitos secundárlos de 9 e de 10 cromossomios.

As minhas observaçóes confirmam, pois, as de PIZA, no que se réfere ao comportamento do cromossómio sexual nos machos dos Proscopildae.

\section{SUMMARY}

Cephalocoema borellii (Giglio-Tos) has 19 chromosomes, that is 9 pairs of autosomes and a single heterochromosome, the latter having been observed either in succession or in synchronism as was the case of the two other species studied by Prof. PIZA, namely Cephalocoema zilkari Piza and Tetanorhynchus mendesi Piza. (= Cephalocoema sica Serv.).

\section{LITERATURA CITADA}

PIZA, s. de Toledo Jor., 1943 - Cromossómios em Proscopiliae (Orthoptera-Acridodea). Rev. Agric. 18:347-350.

PIZA, S. de Toledo Jor., 1945 - Comportamento do Heterocromossomio em alguns Ortopteros do Brasil. An, Esc, Sup. Agr, "Luit de Queiroz", 2:173-207. 

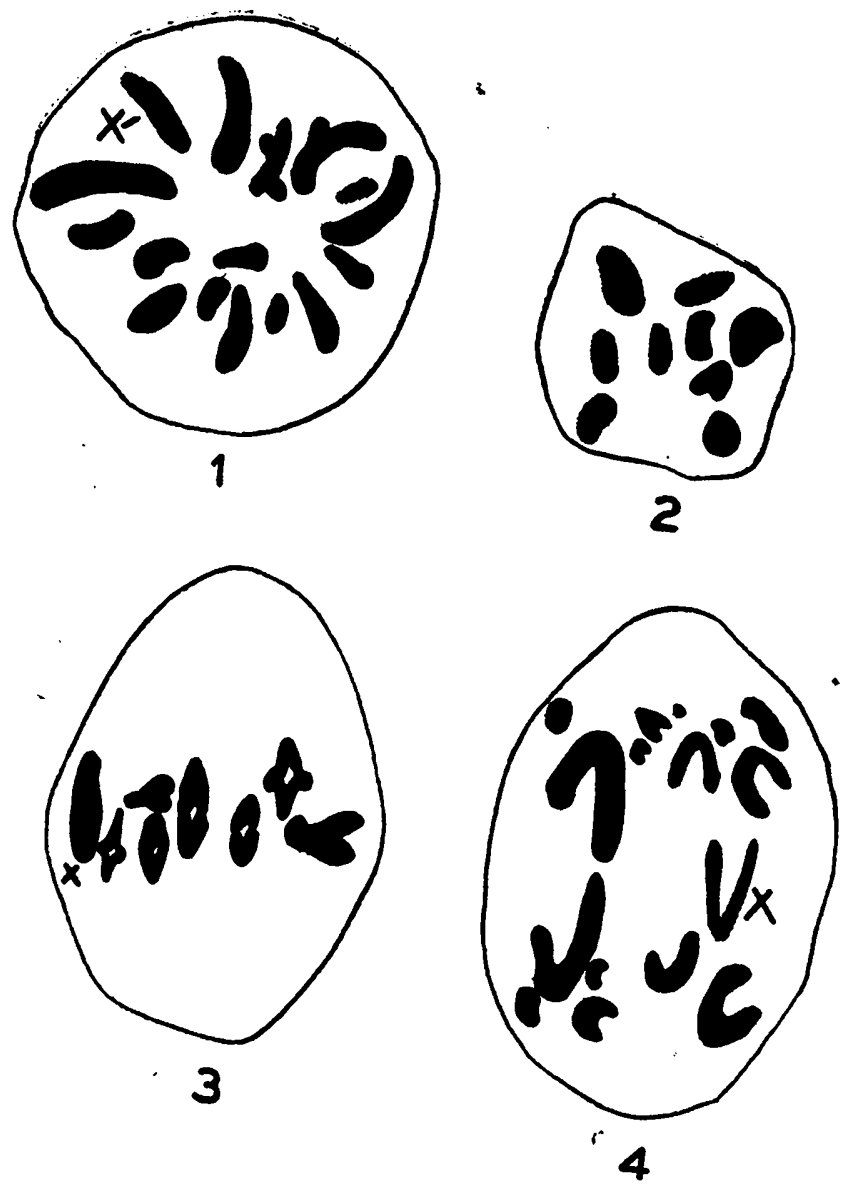

1 - Metáfase do espermatogônio mostrando o heterocromossômio, em bastonete, mais claro e de contôrno menos definido. (x1600). 2 - Metáfase da 1.a divisăo. O heterocromossômio, que é em bastonete, menos colorido, nāo se acha representado. (x2900) . 3 - Vista lateral de uma metáase da 1.a divisão. $O$ heterocromossômio, em bastonete, aparece com os autossómios, na placa equatorial. (x2400) . 4 - Anáfase da 1.a divisão. $O$ heterocrnmossômo, já dividido, aparece em forma de V, entre as placas. (x2400). 


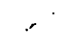

$\vdots$

$\therefore \quad$ : 